\title{
Fracture Distribution Pattern via Numerical Stimulation in Naturally Fractured Shale Gas Reservoir
}

\author{
Zhou Tong, Zhang Shicheng, Zou Yushi, Lin Hun, and Hao Siying
}

\begin{abstract}
Understanding the interaction between hydraulic fractures and natural fractures, and predicting the hydraulic fractures propagation behavior is important to select the best stimulation design and completion strategy in the naturally fractured shale gas reservoirs. This paper introduces a novel numerical simulation model based on the finite element method and discrete element method. Besides in-site stress and the angle of natural fractures, influence on its opening by natural fractures' permeability and adhesive strength are also considered in the meantime. The established model is used to investigate the mechanism of fracture network geometry within a single fracturing stage. The results indicate that with the increasing of horizontal stress difference or adhesive strength and the decreasing of natural fractures' permeability, the influence on hydraulic fractures caused by natural fractures is decreasing, which will generate long major hydraulic fractures and the complexity of the fractures also reduce. Low angle natural fractures system are more easily opened by hydraulic fracture, but once the high angle fracture opened more complex fracture network will be formed. This paper provides improved understanding of complex network fractures generation and a reliable method for the volume fracturing treatment design and the fracture pattern prediction for shale formations.
\end{abstract}

Index Terms-Shale gas, fracture propagation, natural fractures, complex network fractures, fracture complicated index, numerical simulation.

\section{INTRODUCTION}

Horizontal wells are the predominant well type in shale plays today since the ultra low permeability formations can be economically produced only by contacting as much reservoir as possible with hydraulic fracturing treatments. Shale's physical characteristics are sharply different from each other in different regions [1]. The key point of successful shale-gas production lies in whether hydraulic fracturing can connect natural fractures, and form complex network fractures [2]-[4]. Under certain conditions of shale gas reservoirs, carrying out the research on fracture propagation law of hydraulic fracturing, and improving the stimulated reservoirs volume through engineering factors is of great significance for shale gas production.

Micro-seismic monitoring shows that complex fracture networks often appear during hydraulic fracturing treatment of shale gas formation, so the traditional hydraulic fracturing model which is used for simulating double-wing plane fractures is not suitable for simulating complex fractures

Manuscript received February 10, 2016; revised July 27, 2016

The authors are with China University of Petroleum, Beijing, China (email: Zhout1986@126.com, zhangsc@cup.edu.cn, zouyushi@126.com, Linhun016@aliyun.com, 18511900293@163.com). geometric shapes. In recent years, various numerical simulation methods have been used by scholars to research the propagation of complex hydraulic fracturing, so as to provide theoretical basis and technical support for shale gas fracturing design. Olson [5] used simulation 3-dimension displacement discontinuity solution and encoded shale and tight sandstone to find that hundreds of expansions of fracture tips can be simultaneously traced, and that at the position of each fracture tip, the expansion speed is proportional to the stress sensitive coefficient. $\mathrm{Xu}$ et al. [6] used wire-mesh to describe the fracturing fractures in oval balls through orthogonal horizontal, vertical uniform section. Olson et al. [7] adopted boundary element method to create software that researched the fracture form of multi-crack simultaneous expansion, as well as the influence of natural fractures. Chuprakov et al. [8] made a numerical simulation research on the physical mechanism of the mechanical action between natural fractures and pressed hydraulic fractures based on DDM. Weng et al. [4] developed an unconventional fracture model (UFM) in order to research hydraulic fractures propagation law in the fracture development reservoirs. By calculating stress shadow, this model considers the stress interference between the main fractures of neighboring hydraulic fractures and can simulate the mutual action between hydraulic fractures and natural ones. Its calculation results can be corrected by micro-seismic monitoring. Dahi-Taleghani [9], [10] and Keshavarzi [11] used extended finite element method (XFEM) to simulate complex cracks based on 2-dimension plane strain elasticity theory, because XFEM does not need to take fractures as geometry instances, nor does it need to be consistent with the unit boundary. The fracture extension does not need to regroup the network and can simulate random branch fractures and intersecting fractures, so it solved the problem that required a large amount of computation, where FEM is used to constantly regroup network and need to thicken the network near the fractures [12], [13]. But the existing numerical models are mainly based on linear elastic theory, and do not consider the influence of rock plastic deformation. Meanwhile, whether the hydraulic fracture whether turns and propagates along the natural fracture depends on the stress change at the fracture tip, which does not consider that natural fractures can be activated after hydraulic fracture cross it. However, branch fractures also can be formed after hydraulic fracture tips cross natural fractures due to slippage or dilation of natural fractures near the hydraulic fractures caused by fracturing fluid filtration entering the natural fractures. In addition, the numerical simulation of multi-hydraulic fracture propagation is rare under the condition of simulation reservoir natural fractures.

In this study, a novel fracturing model is presented to 
investigate the mechanism of fracture network geometry within a single fracturing stage in a shale formation. Then the model was used to analyze several important parameters which influence the stimulated reservoir volume, such as horizontal differential stress and natural fracture's properties (density, strike angle, and strength). In the meantime, it is believed that this research may provide site construction with a proper extension method that can simulate multidimensional fractures.

\section{MODEL SETUP AND VALIDATION}

\section{A. Fracture Propagation Simulation Methods}

The model consists of the control equation of rock mass, the fracturing fluid flow equation (that is, the equation of continuity) and extended criteria. while rock deformation is mainly based on the linear elastic theory. In order to analyze the shale plastic deformation characteristics, $B$ matrix method should be applied to modify unit stress according to the rule of plastic [14]. The methods to solve and utilize the finite element method and discrete element method is to divide the solved region $\Omega$ into several discrete block units. A virtual spring is used to link each two block units, and convey the mutual interaction forces, and the fractures of springs stands for the cracks of rocks. There is a crack unit between the two block units, which is used to calculate the flow of the fracturing fluid and the distribution of fluid pressure, as an external load. The fluid pressure acts on the crack surface (that is the contact-surface of the block). The finite element method is used to solve continuous block deformation, the discrete element method is used to calculate the spring fracture, and the spring fracture (the expansion of crack) condition is determined by the maximum tensile stress criterion and Mohr coulomb criterion, the model is shown in Fig. 1.

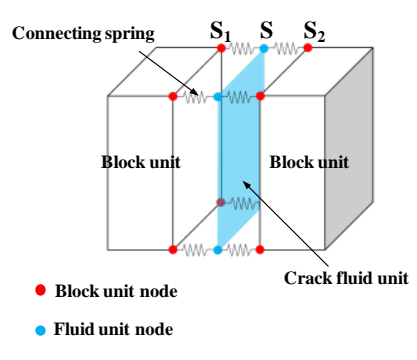

(a)

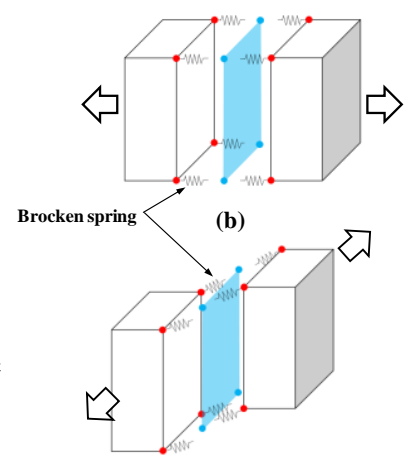

(c)
Fig. 1. Modeling of hydraulic fracture propagation based on finite element method and discrete element method. (a) original state, (b) broken spring after tensile failure, (c) broken spring after shear failure.

Flow equation of fracturing fluid in the crack: If you consider the fracturing fluid in the crack as laminar flow in the tablet of incompressible Newtonian fluid and neglect the effect of gravity, it will meet Poiseuille's law (Equation 1), partial continuous equation (2) and global mass conservation equation (3):

$$
q=-\frac{w^{3}}{12 \mu} \frac{\partial p}{\partial s}
$$

$$
\begin{gathered}
\frac{\partial w}{\partial t}+\frac{\partial q}{\partial s}+q_{l}=0 \\
Q_{0}=\int_{\Omega} \frac{\Delta w}{\Delta t} d s+\int_{\Omega} q_{l} d s
\end{gathered}
$$

In the equations: $p$-the pressure of fluid, $\mathrm{MPa} ; w$-the width of dynamic cracks, $\mathrm{m}$; $t$-time, sec; $q$-volume flow-rate, $\mathrm{m}^{3} / \mathrm{s} ; s$-coordinate of any point within the crack, $\mathrm{m} ; q_{l}$-the amount of fracturing fluid filtration, $\mathrm{m}^{3} / \mathrm{s}$, shale matrix has an ultra-low permeability, in the model, the effect of fracturing fluid filtration is neglected, that is, $q_{l}=0 ; \mu$ fracturing fluid viscosity, $\mathrm{mPa} \cdot \mathrm{s} ; Q_{0}$-operational discharge capacity, $\mathrm{m}^{3} / \mathrm{s}$.

Rock mass control equation: Shale block motion accords with Newton second law. The block may deform and the small displacement of the linear elastic dynamic equation (4) is obtained [15]:

$$
\sigma_{i j, j}+b_{i}-\rho u_{i, t t}-\alpha u_{i, t}=0
$$

In the equation: $\sigma_{i j}=D_{i j s t} \varepsilon_{s t}, \varepsilon_{s t}=\left(u_{i, j}+u_{j, i}\right) / 2, \sigma_{i j}$-Cauchy tensor, $b_{i}$-stamina, $\rho$-rock density, $\alpha$-damping factor, $u_{i^{-}}$ displacement, -strain, $D_{i j s t}$-Hooketensor. Model block boundary $\Gamma_{b}$ is a fixed boundary, $u_{i}=0$; impose contact force and fluid pressure $p_{i}$, on the block crack plane $\Gamma_{f}, \sigma_{i j} n_{j}=p_{i}$.

Brittle shale can be considered as a linear elastic material, and the stress-strain relationship meets the linear elastic constitutive law, but the stress-strain of elastic shale, which has a high content of clay, lower Young modulus, and higher Poisson's ratio, can not be directly considered as a linear elastic relationship. In the model, finite element method is utilized to solve block deformation, and then $B$ matrix method is used to calculate the nonlinear problems in space of stress [14]. First of all, plastic rule should be used to judge whether an element has entered the stage of plastic deformation. If the judgment criterion is met, the element stress should be corrected. The specific process is shown as equation (5).

$$
\left\{\begin{array}{l}
\Delta \varepsilon_{i}=B_{i} \Delta u_{e} \\
\Delta \sigma_{i}=D \Delta \varepsilon_{i} \\
\sigma_{i}^{n}=\sigma_{i}^{n-1}+\Delta \sigma_{i} \\
F_{e}^{n}=\sum_{i=1}^{n} B_{i}^{T} \sigma_{i}^{n} w_{i} J_{i}
\end{array}\right.
$$

In the equation: $B$-train matrix; $\Delta$-each variable's increment of each iterative step; $\sigma^{n}$-stress of the current step, $\sigma^{n-1}$-stress of the former step; $F^{n}$-node load of the element; $w$-weight function, $J$-Jacobi determinant value of the element.

Drucker-Prager yield criterion:

$$
f\left(I_{1}, \sqrt{J_{2}}\right)=\sqrt{J_{2}}-\alpha I_{1}-k=0
$$

In the equation: $I_{1}$ and $J_{1}$ are stress tensor of the first invariant and stress tensor of the second invariant, suppose $\sigma_{1}, \sigma_{2}$, and $\sigma_{3}$ are the maximum principal stress, the intermediate principal stress, and the minimum principal stress, respectively, then:

$$
\begin{gathered}
I_{1}=\sigma_{1}+\sigma_{2}+\sigma_{3} \\
J_{2}=\left[\left(\sigma_{1}-\sigma_{2}\right)^{2}+\left(\sigma_{2}-\sigma_{3}\right)^{2}+\left(\sigma_{1}-\sigma_{3}\right)^{2}\right] / 6
\end{gathered}
$$


$\varphi$ and $c$ are shale's internal friction angle and cohesion, and $\alpha$ and $k$ are Drucker-Prager yield criterion material constant, then the relationship between, $\alpha, k$ and $\varphi, c$ is as follows:

$$
\alpha=\frac{\sin \varphi}{\sqrt{9+3 \sin ^{2} \varphi}}, \quad k=\frac{\sqrt{3} c \cos \varphi}{\sqrt{3+\sin ^{2} \varphi}}
$$

The coupling of fracturing fluid flow and fluid deformation: The relationship between the fracturing fluid flow within the crack and the deformation of the matrix block:

(1) the change of the fluid pressure on the matrix block boundary surface will affect the deformation of the matrix block, and further cause the change of the crack width;

(2) the change of the crack width will cause the flow to change, and finally affect the distribution of fluid pressure in the crack.

As shown in Fig. 1, Node $S$ on the crack unit corresponds to Node $S_{1}$ and Node $S_{2}$ on the two neighboring block units, the normal directions of these two nodes relates to displacement $\Delta u_{n}$, and the tangential directions relate to displacement $\Delta u_{s}$, that is to say, the dynamic width of the crack and the degree of shear dislocation are used as the known conditions of next fluid to calculate the time steps, further to calculate the coupling iteration of fluid pressure field and matrix block deformation. The displacement differences of Point $S$ of crack surface on x, y directions of the global coordinate system are respectively $\Delta u$, and $\Delta v$, then the tangential direction $\Delta u_{s}$, and normal direction $\Delta u_{n}$ built along the crack surface are as follows:

$$
\left(\begin{array}{l}
\Delta u_{s} \\
\Delta u_{n}
\end{array}\right)=\left(\begin{array}{cc}
\cos \theta & \sin \theta \\
-\sin \theta & \cos \theta
\end{array}\right)\left(\begin{array}{l}
\Delta u \\
\Delta v
\end{array}\right)
$$

$\tau_{s}$, the tangential stress, and $\sigma_{n}$, the normal stress of Point $S$ can be shown as follows:

$$
\left(\begin{array}{c}
\tau_{s} \\
\sigma_{n}
\end{array}\right)=\left(\begin{array}{cc}
k_{s} & 0 \\
0 & k_{n}
\end{array}\right)\left(\begin{array}{l}
u_{s}^{(2)}-u_{s}^{(1)} \\
u_{n}^{(2)}-u_{n}^{(1)}
\end{array}\right)
$$

In the equation: $k_{s}$ and $k_{n}$ are tangential rigidity and normal rigidity.

Crack extension criterion: With the constant rising of the fluid pressure at the original crack, the spring connecting the two blocks will extend or shear slip, that is, when the maximum compressive principal stress (the pressure is negative) reaches rock tensile strength (the maximum tensile stress criterion [16]), tensile crack will occur, as shown in equation (12); when Mohr-Coulomb criterion is met, shear crack will occur, as shown in equation (13).

$$
\begin{gathered}
-\sigma_{1}>\sigma_{T} \\
|\tau|>\tau_{0}+\tan \varphi \sigma_{n}^{\prime}
\end{gathered}
$$

In the equation: $\sigma_{l}$-maximum compressive principal stress; $\sigma_{T}$-tensile strength; $\tau_{0^{-}}$-cohesion; $\varphi$-internal friction angle; $\sigma_{n}^{\prime}$-crack surface normal direction effective compressive stress.

\section{B. Comparison to PKN Model}

This numerical model was compared with the following a limiting cases for validation: a simple bi-wing hydraulic fracture. Several constant parameters were set as follows: $\mu=10 \mathrm{mPa} \cdot \mathrm{s}, Q_{t}=5 \mathrm{~m}^{3} / \mathrm{min}, \sigma_{v}=50 \mathrm{MPa}$, and $\sigma_{\text {hmin }}=45 \mathrm{MPa}$, respectively. Table I lists the basic shale properties used in the numerical simulations. This fracture length was then compared with that calculated by the Perkins-KernNordgren (PKN) model without leak-off [17], [18], and an error of $9.8 \%$ was found to have been generated as shown in Fig. 2. The simplistic PKN model not only disregarded fluid leak-off, but also made no consideration of fracture mechanics by assuming that the growing fracture had a constant height; thus, net pressure increased repeatedly with increasing injection time, resulting in a high growth rate of the fracture length.

TABLE I: INPUT PARAMETERS OF MATRIX BLOCKS FOR FRACTURE

\begin{tabular}{|l|c|c|}
\hline \multicolumn{1}{|c|}{ Parameter } & Unit & Value \\
\hline Density, $\rho$ & $\mathrm{kg} / \mathrm{m}^{3}$ & 2600 \\
\hline Permeability, $k$ & $\mu \mathrm{D}$ & 0.5 \\
\hline Young's modulus, $E$ & $\mathrm{GPa}$ & 36.0 \\
\hline Poisson's ratio, $v$ & decimal & 0.225 \\
\hline Tensile strength, $T_{0}$ & $\mathrm{MPa}$ & 6.5 \\
\hline Cohesion, $S_{0}$ & $\mathrm{MPa}$ & 13.0 \\
\hline Frictional angle, $\varphi$ & $\circ$ & 37.5 \\
\hline
\end{tabular}

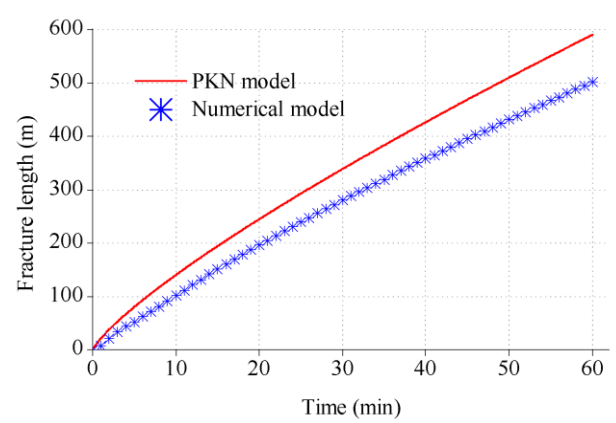

Fig. 2. Comparison of numerical model and PKN model for a simple biwing $\mathrm{HF}$.

\section{NATURAL FRACTURE ACTIVATION CONDITIONS}

Fracturing experiments [19] have shown that horizontal differential stress and the intersection angle between hydraulic fractures and natural fractures are the main geological factors that may decide whether natural fractures can be induced and opened by hydraulic fractures. Rice paper, printer paper and wrapping paper was used to simulate natural fractures of different strengths, and the experiment shows that cohesion and internal frictional angle also play a crucial part for the propagation geometry of hydraulic fractures [20]. In order to research the interaction angle between hydraulic fractures and natural fractures under the condition of different natural fracture properties, the preset natural fracture permeability of the model is $0.001 \sim 10 \times 10^{-3} \mu^{2}$, the cohesion is $0.0 \sim 4.0 \mathrm{MPa}$, and the internal frictional angle is $10 \sim 40^{\circ}$.

Fig. 3 show several representative numerical simulation results of $\mathrm{HF}-\mathrm{NF}$ interactions at different values of the intersection angle $\theta$ and horizontal differential stress $\Delta \sigma$. The curves in the Figs. 4 are the critical line of natural fracture's opening. The hydraulic fracture is more likely to 
open the natural fracture and grow along them below the critical line, whereas the HF is more likely to cross over the natural fracture.

Results show that with the decrease of natural fracture permeability or increase of cementing strength, the natural fracture can be opened under the condition of lower horizontal differential stress and smaller intersection angle, as shown in Fig. 4 and Fig. 5. For example, when the intersection angle is fixed, lower horizontal differential stress is required to initiate a fracture as permeability decreases. As seen in Fig. 4, setting intersection angle at $60^{\circ}$, stress within $6.5 \mathrm{MPa}$ is required to initiate a fracture with a permeability of $1.0 \mathrm{mD}$, whereas $3.5 \mathrm{MPa}$ is at most for the case of $0.001 \mathrm{mD}$.

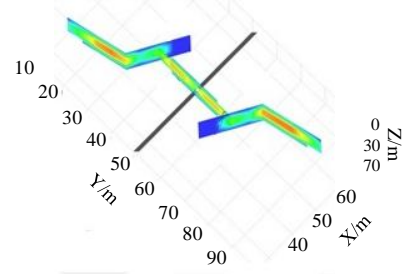

(a) $\Delta \sigma=5 \mathrm{MPa}, \theta=60^{\circ}$

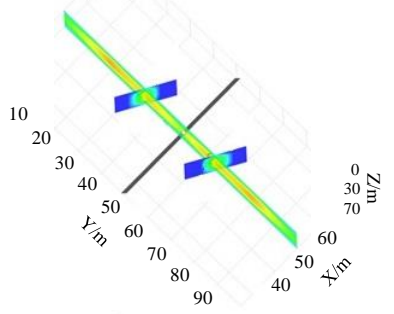

(c) $\Delta \sigma=7 \mathrm{MPa}, \theta=60^{\circ}$

Fig. 3. Interactions between pre-existing natural fracture and the advancing hydraulic fracture at different values of horizontal differential stress and intersection angle.

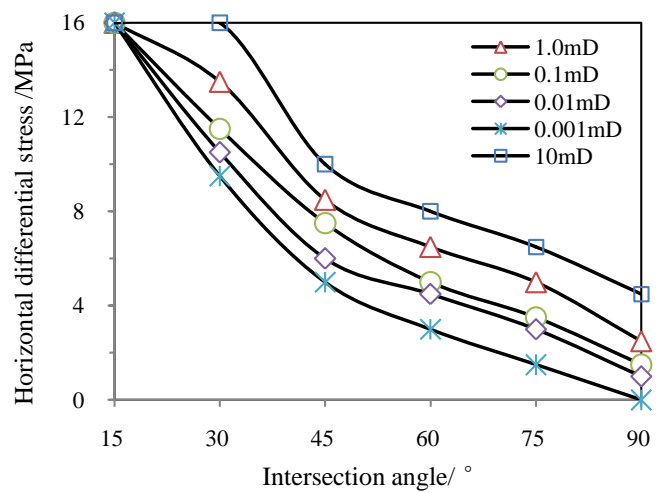

Fig. 4. The effect of permeability on natural fracture's opening.

Natural fracture activation will occurs if the normal stress acting on the fracture plane is reduced or if the coefficient of friction is low, and the shear stress exceeds the shear strength of the fracture [21]. The existing numerical models [4]-[10] ignore the influence of natural fracture permeability. Actually, due to the fluid filtration, normal stress acting on the fracture plane decreases, and slippage or dilation occurs. Branch fractures form with the shear instability of natural fractures near the hydraulic fractures. On the other hand, the fracturing fluid may play the role of lubrication, the friction coefficient will also gradually decrease. However, the friction coefficient of the natural fracture is assumed constant in the model, which means that the influence on the natural fracture activation behavior of changing friction coefficient during injection is not considered.

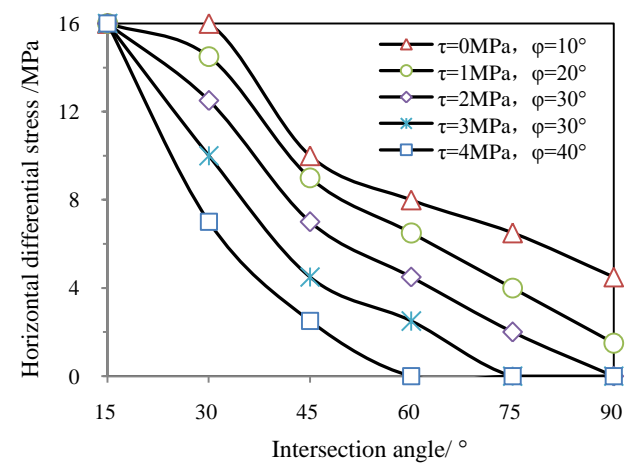

Fig. 5. The effect of cementing strength on natural fracture's opening

\section{RESUltS AND DisCUSSION}

Although it is difficult to uniquely characterize the fracture complexity, it may be helpful to evaluate the degree of fracture complexity with a simple approximation fracture complexity index $(F C I) . F C I$ is the ratio of micro-seismic cloud's total length and total width [22]. In this paper, FCI is calculated by the fracture band width and the fracture length of a single frac stage obtained from numerical simulation $\left(F C I=x_{n} / 2 x_{f}, x_{n}\right.$-fracture band width, $\mathrm{m}, x_{f}$-half length of the fracture, $\mathrm{m})$. The fracture network behavior of shale gas reservoir is simulated and analyzed from two aspects, namely, geology and engineering, based on complex fracture propagation model and discrete natural fracture model. The input parameters of matrix blocks for fracture network propagation model as shown in Table I.

\section{A. Effects of Horizontal Differential Stress}

The complexity of the fracture network is directly related to the horizontal differential stress, the hydraulic fractures under the condition of low stress difference tend to go along the slightest natural fractures [19], [20]. With the increase of horizontal stress, long and straight major fractures are easy to generate, which will connect more natural fractures, and form more complex fractures, while under the condition of high stress difference, only single wing fractures can be generated.

Numerical simulation calculation parameters: natural fracture angle $0 \sim 90^{\circ}$, linear density $0.15 \mathrm{~m} / \mathrm{m}^{2}$, weak cementation (internal frictional angle $25^{\circ}$ and cohesion 3.75 $\mathrm{MPa}$ ); pumping rate $12 \mathrm{~m}^{3} / \mathrm{min}$, fracturing fluid viscosity $5 \mathrm{mPa} \cdot \mathrm{s}$, cluster spacing $20 \mathrm{~m}$, single stage four cluster fracturing. The calculation results of different levels of horizontal differential stress are shown in Fig. 6. Under the condition of low level stress differences, the formation of hydraulic fractures is easily influenced by natural fractures. Generally, complex short fractures with high density and low fracture width will be formed by fracturing. When the horizontal differential stress is $3 \mathrm{MPa}$, the $F C I$ is 0.69 (the maximum calculation fracture length is $297 \mathrm{~m}$, the band width of the fracture is $205 \mathrm{~m}$ ). The fracturing band width is too high, which will lead to the merge of fractures between segments and fractures between clusters, and may finally reduce the efficiency of fracture treatment. With the increase of horizontal differential stress, the influence caused by 
natural fractures on hydraulic fractures will decrease, which may favor the generation of long hydraulic fractures. When the horizontal differential stress is $10 \mathrm{MPa}$, the major fractures formed are mainly long, the complexity of the fractures will also decrease obviously, and the FCI is only 0.24 . The numerical simulation results are similar to the Experimental research [19], [20].
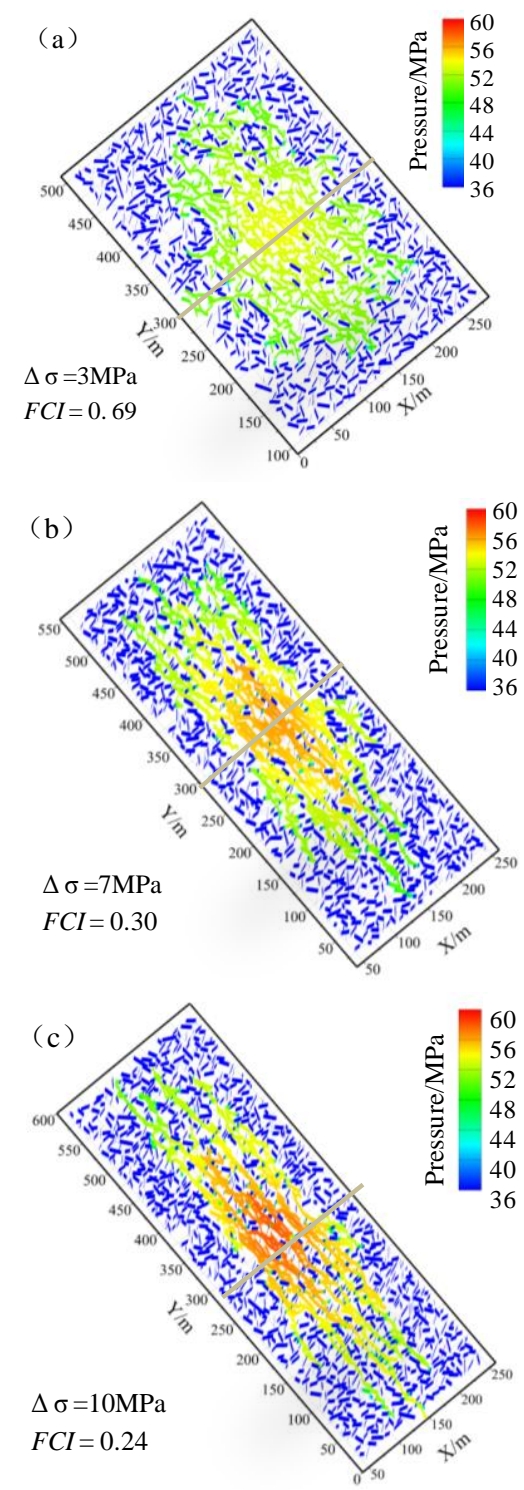

Fig. 6. Fracture geometry for different horizontal stress bias (The minimum horizontal stress is oriented parallel to the $\mathrm{x}$-direction, and the maximum horizontal stress is oriented parallel to the y-direction).

\section{B. Effects of NF Angle}

Different fracture geometry might formed during hydraulic fracturing in a naturally fractured reservoir due to the difference of the angle, density and mechanical characteristics of natural fractures system. Natural fracture angle is one of the most important factors which decide whether natural fracture can be opened by hydraulic fracture, and it has a great effect on fracture geometry and complexity. According to natural fracture activation conditions, when the preset natural fracture permeability is $1.0 \times 10^{-3} \mu^{2}$, various angles of natural fracture can be opened under the horizontal stress difference of 5MPa. In this condition, the angle of natural fracture system in the model was varied to demonstrate the influence of the natural fracture system angle to fracture geometry. The green and red rectangles in Fig.7 represent the tensile and shear fractures generated during fracturing treatments.

As can be seen in Fig. 7, with the angle of natural fracture system increasing from $0 \sim 30^{\circ}$ to $60 \sim 90^{\circ}, F C I$ will increase from 0.23 to 0.57 . Comparatively, lower angle natural fractures system are more easily opened by hydraulic fracturing, but the steering radius and influence scope are far lower than that of the higher angle. This means that once the higher angle fracture opens, more complex fracture networks will be formed, but stronger in-situ stress anisotropy prevents higher angle natural fractures from connecting with hydraulic fractures.
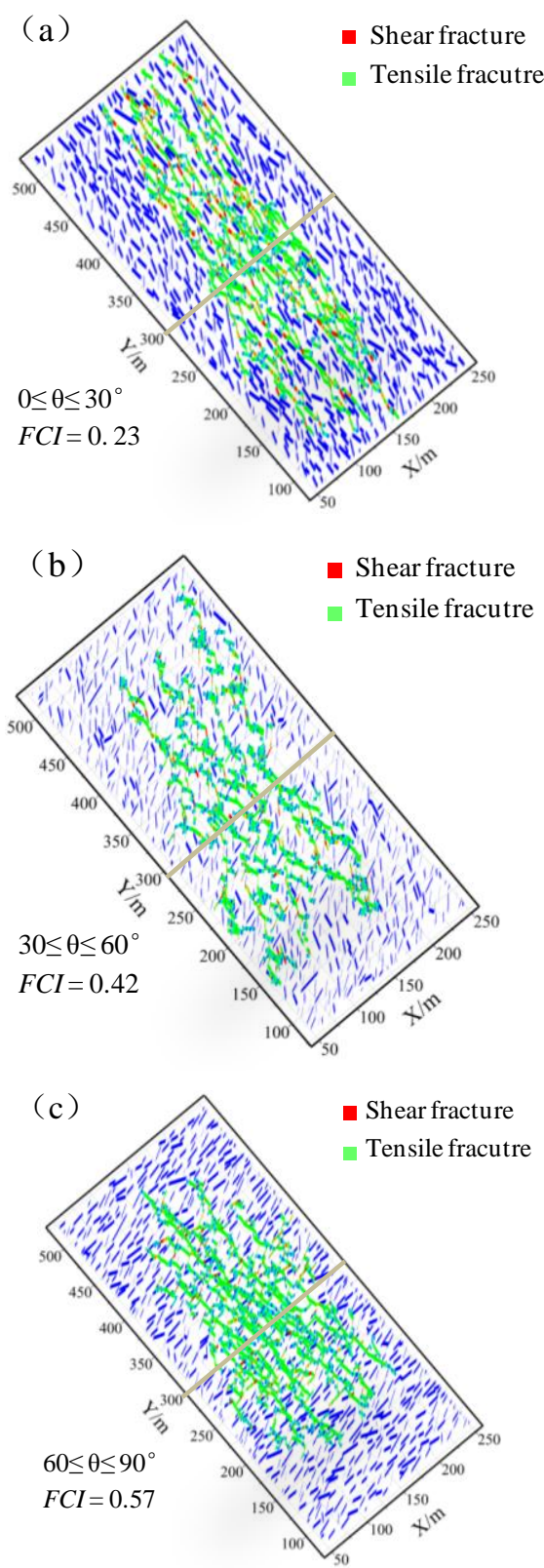

Fig. 7. Fracture geometry for different angle of natural fractures.

\section{Effects of NF Strengths}

Composite amplitude ratios from both shale and tight gas sand fracturing treatments in North American reservoirs show that pure tensile opening mechanism along with a hybrid source of $50 \%$ strike-slip shear and $50 \%$ tensile opening [23]. Under the condition of 5MPa horizontal stress difference, the simulated results of the influence of different 
$\mathrm{NF}$ strengths on the distribution of hydraulic fracture are shown in Fig. 8. Tensile fracture and shear fracture both exist during fracturing in natural fractured reservoir. The shear failure mainly occurred in the natural fractures and is proportional to the complexity of fractures. When the NF strengths are close to the matrix, tensile damage has the leading role and only a small number of low angle natural fractures are open. FCI is about 0.29 . With the decrease of the NF strengths, the number of the shear fracture opening is increased obviously, and the complexity of the fracture is significantly increased. The $F C I$ is increased to 0.52 . The fracture geometry alters from that of multiple branches to a highly complex network when the NF strength changes from strong to weak. Therefore, the setting of mechanical parameters of natural fractures in numerical simulation has a significant impact on the stimulated region, which will directly affect the prediction results of the fracture geometry.
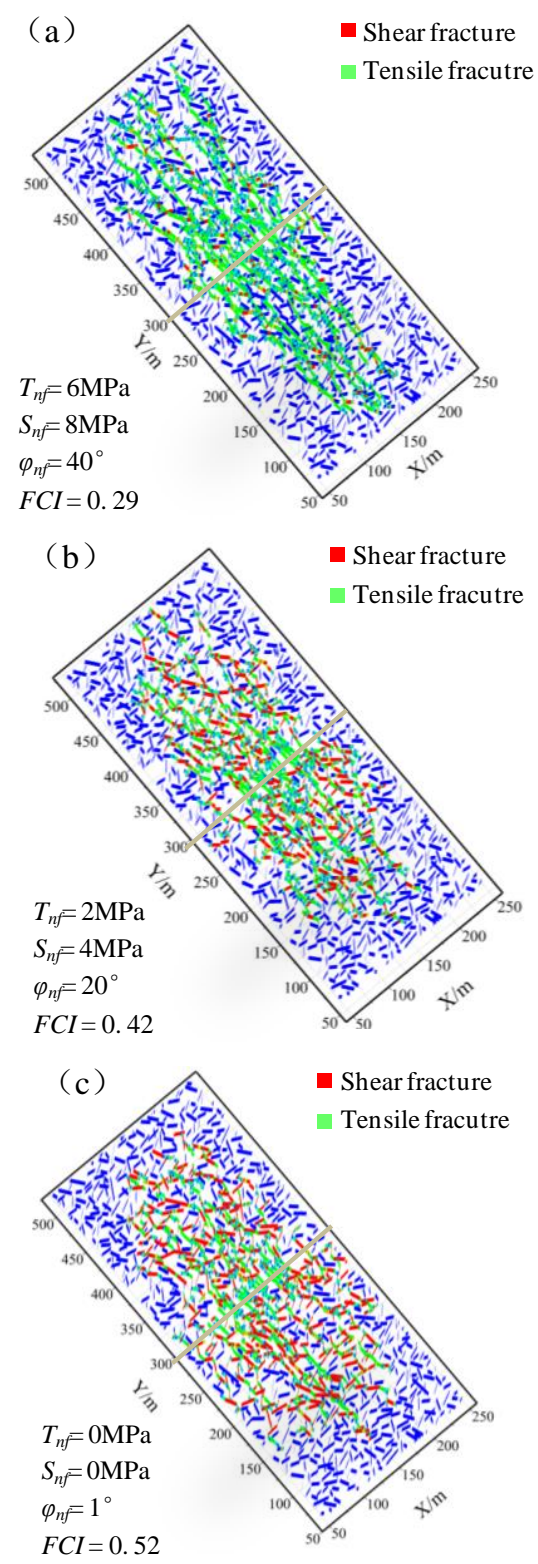

Fig. 8. Fracture geometry for different cementing strength of natural fractures.

\section{Effects of NF Permeability}

The permeability of natural fractures is set into three

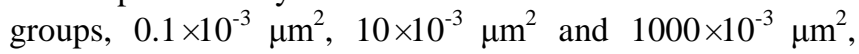

respectively. The simulation results of the fracture propagation geometry of the single stage four cluster fracturing are shown in Fig. 9. When the horizontal stress difference is $5 \mathrm{MPa}$, the resulting hydraulic fracture network became longer, narrower, and less complex with a decreased value of NF permeability. The FCI from 0.42 of the $1000 \times 10^{-3} \mu^{2}$ decreases to 0.38 of the $0.1 \times 10^{-3} \mu \mathrm{m}^{2}$. Therefore, the filtration of the fracturing fluid into the natural fractures can improve the fracture pressure and it also can promote the occurrence of natural fractures sliding or expansion to develop branch fractures.
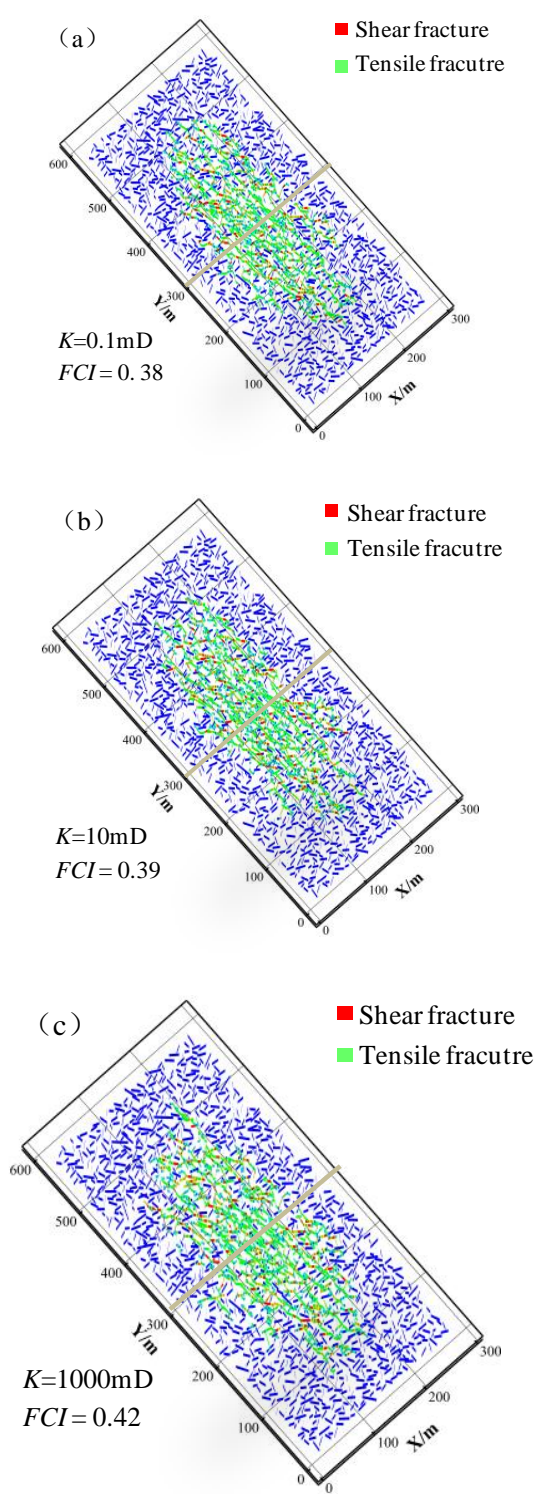

Fig. 9. Fracture geometry for different permeability of natural fractures.

\section{E. Effects of NF Distribution}

In the simulation, the natural fracture linear density is set into three groups $\left(0.15 \mathrm{~m} / \mathrm{m}^{2}, 0.015 \mathrm{~m} / \mathrm{m}^{2}\right.$ and $0.075 \mathrm{~m} / \mathrm{m}^{2}$ respectively) at a given $5 \mathrm{MPa}$ horizontal stress difference, and the natural fracture angle is random (range from $0^{\circ}$ to $90^{\circ}$ ). The distribution of hydraulic fractures is relatively uniform when the natural fracture is distributed, as shown in Fig. 10a. By contrast, Fig. 10b and Fig. 10c shows that hydraulic fracture network propagated non-uniformly within a fracturing stage. All dense branching fractures propagated from perforation clusters located in regions containing high- 
density natural fractures and that multi-fractures, or even simple fractures, propagated in regions containing lowdensity natural fractures. The simulation results imply that more perforation clusters should be placed in regions with low-density natural fractures to achieve the uniform development of hydraulic fracture network within a fracturing stage.
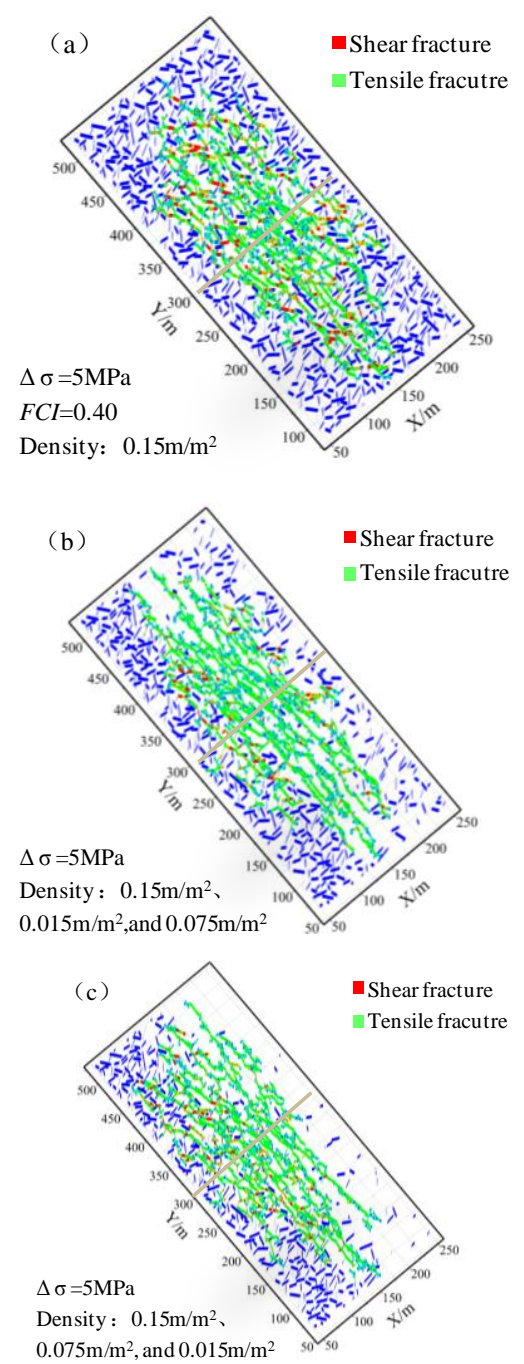

Fig. 10. Fracture geometry for different distribution of natural fractures.

\section{CONCLUSION}

Stimulations of hydraulic fracturing with surrounding natural fractures were studied by a mixed method of finite elements and discrete elements, the main results are as follows:

(1) Horizontal differential stress dominates the hydraulic fracture pattern. With the increase of horizontal stress difference, the influence on hydraulic fractures caused by natural fractures decreases. When the horizontal stress difference is larger than $10 \mathrm{MPa}$, the fractures formed are mainly long. The width of the reformed fracture belt significantly decreases, and the complexity of the fractures also decreases.

(2) Natural fracture angle is one of the most important factors which determine whether natural fracture can be opened by hydraulic fracture, and can have a great effect on fracture geometry. Comparatively, low angle natural fractures system are more easily opened, but the steering radius and influence scope is much lower than the high angle. Once the high angle natural fracture is opened, a more complex fracture network will be formed.

(3) Permeability and adhesive strength (such as cohesion, frictional factor and tensile strength) of natural fractures are very important factors for fractures opening.

(4) The distribution of natural fracture system may determine the development of hydraulic fractures. To realize the uniform development of hydraulic fracture network, perforation clusters should be placed according to the distribution of natural fractures within a fracturing stage.

(5) Complex fracture network generated by hydraulic fracture and natural fracture systems during multi-cluster staged fracturing of a horizontal well, which made the shale highly "cut", and become a kind of discontinuous medium. The characteristics of discrete element and finite element mixed method can effectively deal with the fracture of this kind of complex medium.

\section{ACKNOWLEDGMENT}

This work was supported by the National Basic Research Program of China (no. 2013CB228004).

\section{REFERENCES}

[1] C. Jia, S. Li, H. Wang, and T. Jiang, "Experiments and researches on network fracturing of shale gas reservoir," Engineering Science, vol. 14, pp. 106-112, 2012.

[2] T. Zhou, S. Zhang, and Y. Feng et al., "Experimental study of permeability characteristics for the cemented natural fractures of the shale gas formation," Journal of Natural Gas Science and Engineering, vol. 29, pp. 345-354, 2016.

[3] Y. Tang, J. Zhang, Q. Zhang, and P. Long, "An analysis of hydraulic fracturing technology in shale gas wells and its application," Natural Gas Industry, vol. 30, pp. 33-38, 2010.

[4] X. Weng, O. Kresse, C. Cohen, R. Wu, and H. Gu, "Modeling of hydraulic fracture network propagation in a naturally fractured formation," presented at the SPE Hydraulic Fracturing Technology Conference, Texas, USA, January 24-26, 2011.

[5] J. E. Olson, "Multi-fracture propagation modeling: Applications to hydraulic fracturing in shales and tight gas sands," presented at the 42nd US Rock Mechanics Symposium and 2nd U.S.-Canada Rock Mechanics Symposium, June 29-July 2, 2008.

[6] W. Xu, M. Thiercelin, and I. Walton, "Characterization of hydraulically-induced shale fracture network using an analytical/semi-analytical model," presented at the SPE Annual Technical Conference and Exhibition, Louisiana, USA, October 4-7, 2009 .

[7] J. E. Olson and Dahi-Taleghani, "Modeling simultaneous growth of multiple hydraulic fractures and their interaction with natural fractures," presented at the 2009 SPE Hydraulic Fracturing Technology Conference, Texas, USA, January 19-21, 2009.

[8] D. A. Chuprakov, A. V. Akulich, E. Siebrits, and M. Thiercelin, "Hydraulic-fracture propagation in a naturally fractured reservoir," presented at the SPE Oil and Gas India Conference and Exhibition held in Mumbai, India, January 20-22, 2010.

[9] Dahi-Taleghani and J. E. Olson, "Numerical modeling of multistranded hydraulic fracture propagation: Accounting for the interaction between induced and natural fractures," presented at the 2009 SPE Annual Technical Conference and Exhibition, Louisiana, USA, October 4-7, 2009.

[10] Dahi-Taleghani, "Fracture re-initiation as a possible branching mechanism during hydraulic fracturing," presented at the 44th US Rock Mechanics Symposium and 5th U.S.-Canada Rock Mechanics Symposium, Salt Lake City, UT, June 27-30, 2010.

[11] R. Keshavarzi, S. Mohammadi, and H. Bayesteh, "Hydraulic fracture propagation in unconventional reservoirs: The role of natural fractures," presented at the 46th US Rock Mechanics/ Geomechanics Symposium, Chicago, IL, USA, June 24-27, 2012.

[12] T. N. Bittencourt and P. A. Wawrzynek, "Quasi automatic simulation of crack propagation for 2D LEFM problem," Engineering Mechanics, vol. 55, pp. 321-33, 1996. 
[13] L. F. Martha, "Topological and geometrical modeling approach to numerical discrietization and arbitrary fracture simulation in three dimensions," Comell University, Ithaca N.Y. 1999.

[14] Itasca Consulting Group Inc, Fast Lagrangian Analysis of Continuc Theory and Background, Minneapolis, USA: Itasca Consulting Group, 2005.

[15] Y. Liu, S. Li, and X. Liu, "Coupled fluid flow and stress computation model of dual media based on continuum-medium distinct element method," Chinese Journal of Rock Mechanics and Engineering, vol. 30, pp. 951-959, 2011.

[16] F. Erdogan and G. Sih, "On the crack extension in plates under loading and transverse shear," Journal of Fluids Engineering, vol. 85 , pp. 519-527, 1963 .

[17] R. P. Nordren, "Propagation of a vertical hydraulic fracture," $S P E$ Journal, vol. 12, no. 4, pp. 306-314, 1972.

[18] T. K. Perkins and L. R. Kern, "Widths of hydraulic fractures," Journal of Petroleum Technology, vol. 13, pp. 937-949, 1961.

[19] L. B. Thomas, "An experimental study of interaction between hydraulically induced and pre-existing fracturing," presented at the SPE/DOE Unconventional Gas Recovery Symposium of the Society of Petroleum Engineers, Pittsburgh, PA, May 16-18, 1982.

[20] J. Zhao, M. Chen, Y. Jin, and G. Zhang, "Analysis of fracture propagation behavior and fracture geometry using a tri-axial fracturing system in naturally fractured reservoirs," Int. J. Rock Mech. \&Min. Sci, vol. 45, pp. 1143-1152, 2008.

[21] B. N. Nagel and L. Byungtark, "Gas shale hydraulic fracturing: A numerical evaluation of the effect of geomechanical parameters," presented at the SPE Hydraulic Fracturing Technology Conference, The Woodlands, Texas, USA, February 6-8, 2012.

[22] C. L. Cipolla, N. R. Warpinski, M. J. Mayerhofer, and M. C. Vincent, "The relationship between fracture complexity, reservoir treatment and fracture treatment design," presented at the SPE Annual Technical Conference and Exhibition, Denver, Colorado, USA, September 21-24, 2008.

[23] S. C. Maxwell and C. L. Cipolla, "What does microseismicity tell us about hydraulic fracturing?" presented at the SPE Annual Technical Conference and Exhibition, Denver, Colorado, USA, October 30November 2, 2011.

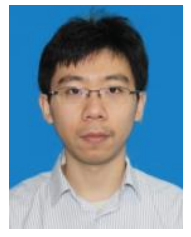

Zhou Tong is a $\mathrm{PhD}$ candidate in the College of Petroleum Engineering, China University of Petroleum, Beijing. He holds a MS degree in oil-gas field development engineering from China University of Petroleum, Beijing. His major field of study is in unconventional reservoirs development.

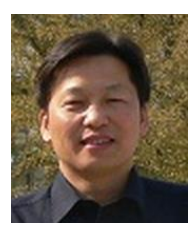

Zhang Shicheng is a professor in the College of Petroleum Engineering, China University of Petroleum, Beijing. Zhang holds a BS degree in oil production engineering from East China Petroleum Institute, MS and $\mathrm{PhD}$ degrees in oil-gas field developmen engineering from China University of Petroleum, Beijing. He has served on the editorial committees of several journals and has authored or coauthored more than 80 technical papers.

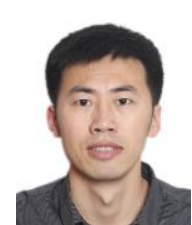

Zou Yushi is a lecturer in the College of Petroleum Engineering, China University of Petroleum, Beijing. He holds an MS and $\mathrm{PhD}$ degrees in oil-gas field development engineering from China University of Petroleum, Beijing. He has published over 10 academic articles in academic periodicals home and abroad.

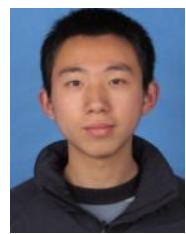

Lin Hun is a $\mathrm{PhD}$ candidate in the College of Petroleum Engineering, China University of Petroleum, Beijing. He holds a MS degree in oil-gas field development engineering from China University of Petroleum, Beijing. His major field of study is in numerica simulation and unconventional reservoirs development.

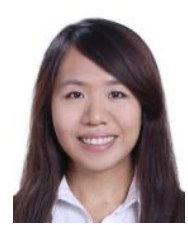

Hao Siying is a master in the College of Petroleum Engineering, China University of Petroleum, Beijing. Her research mainly centers around unconventional oil and gas well stimulation techniques and reservoirs simulation studies. 